\title{
Evolução Humana e Religião: Opiniões de Jovens Brasileiros e Italianos
}

\section{Human Evolution and Religion: Opinions of Brazilian and Italian Teenagers}

\author{
Graciela da Silva Oliveira \\ Nelio Bizzo \\ Brasil \\ Giuseppe Pellegrini \\ Brasil \\ Itália
}

Este trabalho teve como objetivo verificar a aceitação da explicação científica para a origem humana por estudantes brasileiros e italianos, e as relações das suas opiniões com a religião. Os dados foram coletados através de um questionário intitulado Barômetro e analisados com o auxílio do Software Statistical Package for Social Science (SPSS) versão 18.0. Os resultados sugerem que os jovens brasileiros e italianos atribuem valor à religião e se identificam com grupos religiosos. Quanto à aceitação da evolução humana, os jovens italianos estão mais dispostos a assumir uma posição científica para a própria origem, ao passo que as influências de crenças pessoais foram mais intensas nas respostas dos jovens brasileiros. Entre alguns estudantes italianos verifica-se a intervenção de ideias teístas; no caso do Brasil antes de influências religiosas ressaltam-se defasagens de conhecimentos científicos.

Palavras-chave: Evolução biológica; Origem humana; Ensino Médio.

The aim of this study was to verify the acceptance of the scientific explanation about human origin by Brazilian and Italian students and how their opinions relate to religion. The data collection was in the form of a questionnaire entitled Barometer and the analysis was done using the Statistical Package for Social Science Software (SPSS) version 18.0. The results suggest that both Brazilian and Italian teenagers value religion and identify with religious groups. Concerning the acceptance of human evolution, the Italian teenagers are more likely to assume a scientific stand for human origin, whereas the influence of personal beliefs were more intense in the answers provided by the Brazilian teenagers. In Italy, it is possible to observe the intervention of theistic ideas in some students' opinions. In Brazil, on the other hand, the lack of scientific knowledge is stronger than religious influences.

Keywords: Biological evolution; Human origin; High School. 


\section{Introdução}

O objetivo da presente pesquisa foi verificar a aceitação da explicação científica para a origem humana por estudantes brasileiros e italianos, e as possíveis relações entre as opiniões dos jovens com a religião.

O ensino da evolução biológica parece controverso em muitos países, principalmente por causa do aparente conflito com crenças e doutrinas religiosas. Inevitavelmente, a controvérsia social em torno do ensino do tema surge nas salas de aulas. Por exemplo, nos Estados Unidos, a evolução biológica tornou-se um assunto político, e, em alguns países da Europa, são relatados incidentes aparentemente em ascensão, motivados por grupos islâmicos (Boujaoude; Wiles; Asghar; Alters, 2011). Na literatura, verifica-se que diversos fatores parecem influenciar as relações do público em geral com a teoria evolutiva. Trata-se de um assunto com perfil controverso, no sentido de que questões culturais parecem influenciar a percepção do indivíduo, diferentemente do que acontece com outros temas científicos. Assim, para compreender as percepções de estudantes e professores sobre teoria da evolução é preciso promover investigações que permeiem uma variedade de fatores que podem influenciá-las (Hokayem; Boujaoude, 2008).

À medida que os jovens manifestam suas opiniões sobre temas científicos, é possível inferir o papel da escola, da comunidade e das crenças pessoais sob sua visão de mundo. De acordo com Kearney (1984), a sociedade contribui na construção de visão de mundo pelo indivíduo, a partir de um processo constante de análise de si próprio à luz do meio ambiente. Desta forma, a escola contribui com o ensino de temas científicos e representa uma visão de mundo científica. Entretanto, em conjunto com a escola, atuam diversos meios de comunicação e socialização que devem resultar em diferenças nas visões de mundo entre os estudantes.

Cobern (1991) argumenta que estudantes de um mesmo grupo cultural devem apresentar diferentes relações com temas científicos apresentados em sala de aula. Enquanto alguns grupos reconhecem a validade de conceitos científicos, outros, possivelmente, perceberão contradições entre os conceitos apresentados na escola e suas experiências e crenças pessoais, favorecendo a rejeição de temas que não encontram um lugar na cultura dos estudantes, isto é, a aprendizagem de conceitos científicos deverá acontecer se fizerem sentido dentro desse meio cultural.

Assim, pontuar os temas da teoria da evolução biológica que alguns jovens reconhecem como válidos constituiu um importante passo para a apreciação das construções e relações entre diversas visões de mundo. Além disso, estudos comparativos acerca das opiniões de jovens sobre a teoria evolutiva, desenvolvidos em diferentes países com amostras de grande escala são escassos. No Brasil, há poucas experiências que envolvem amostras nacionais, assim como na Itália, conforme Crivellaro e Sperduti (2014).

Desta forma, considerou-se que estudos de representatividade nacional associados a análises internacionais ampliam as possibilidades de discussões sobre o ensino de 
Ciências em um contexto global. Ao dar voz aos jovens e atenção às suas percepções e opiniões, é possível constituir indicadores dos elementos de visão de mundo, bem como compreender o universo de variáveis que interferem na formação das atitudes de jovens em relação à Ciência da atualidade.

\section{Método}

A pesquisa aconteceu nos dois países simultaneamente, a partir da aplicação de um instrumento de coleta de dados com itens comuns, no primeiro semestre de 2014 . Após a seleção da população-alvo, a construção e validação do instrumento de coleta de dados, iniciou-se o desenvolvimento da logística para aplicação dos questionários, e optou-se pelas seguintes etapas: 1) Composição de uma equipe de pesquisa responsável pela coleta de dados; 2) Contatos com as escolas e solicitação de professores colaboradores; 3) Aplicação e devolução dos questionários executadas pelos professores colaboradores, sob orientação da equipe de pesquisa. No Brasil, em função das dimensões geográficas e do sorteio de escolas em regiões díspares, fez-se o envio e a devolução dos questionários por correio; enquanto na Itália a equipe de pesquisa visitou pessoalmente escolas para as coletas de dados.

\section{Brasil}

No Brasil compôs-se uma amostra de representatividade nacional de estudantes matriculados no $1^{\circ}$ ano do Ensino Médio. Para o sorteio da amostra, foi utilizado o processo de amostragem estratificada por conglomerados em dois estágios: escola e turma. Inicialmente foram sorteadas 15 escolas em cada região, com base no banco de dados do Ministério de Educação, e com auxílio de gerador de números aleatórios do software Microsoft Office Excel versão 2010. Esperava-se, dessa forma, que fossem incluídas na amostra 75 escolas do país. Para prevenir os efeitos da não resposta na precisão das estimativas, foi sorteado um número maior de escolas. Considerando-se que a não resposta fosse da ordem de $25 \%$, foram sorteadas 20 escolas em cada região, totalizando 100. A composição da amostra final por região foi: 573 estudantes do CentroOeste (23,8\%); 505 do Nordeste (21\%); 480 do Norte (20\%); 433 do Sul (18\%) e 413 do Sudeste (17,2\%).

A amostra era proveniente de 78 escolas (públicas e privadas), localizadas em 72 municípios de diferentes regiões do país, totalizando 2.404 estudantes, sendo $55,1 \%$ de meninas; e na faixa de 15 anos de idade (47,4\%).

Inicialmente, foram feitos contatos telefônicos com as escolas sorteadas pela equipe de pesquisa, seguido do envio formal da apresentação do projeto de pesquisa pelo endereço eletrônico da escola. Os contatos telefônicos aconteceram entre os meses de março e maio de 2014, com as 100 escolas sorteadas. Contudo, nos contatos iniciais, algumas se recusaram a participar e, por isso, utilizou-se uma lista reserva de escolas sorteadas $(\mathrm{N}=20)$ a fim de garantir o envio dos questionários a 100 escolas, como estipulado no plano amostral. 
Nas escolas, os questionários foram aplicados pelos professores colaboradores entre os meses de maio e julho de $2014 \mathrm{em}$ turmas de $1^{\circ}$ ano do Ensino Médio. A aplicação dos questionários aconteceu em sala de aula, e a maioria dos professores declarou que 30 minutos foram suficientes para apresentação dos objetivos, esclarecimentos sobre preenchimento, distribuição e obtenção das respostas dos estudantes.

\section{Itália}

A população de estudo da Itália foi constituída por alunos que estavam cursando $\mathrm{o} 2^{\circ}$ ano do segundo ciclo do Ensino Secundário, matriculados em escolas caracterizadas como Liceos - clássico, científico, linguístico e artístico - e Técnicos Profissionalizantes.

A estrutura e a organização do sistema escolar da Itália dividem-se em: Ensino Infantil, que atende a estudantes entre 2 e 5 anos, período escolar não obrigatório; Ensino Primário, subdividido em cinco etapas, que compreende a faixa etária entre 6 e 10 anos; Ensino Secundário, subdividido em dois ciclos, no total de 8 anos, que atendem a jovens entre 11 e 19 anos de idade.

Para definição do plano amostral, utilizou-se da amostragem estratificada e obteve-se uma representatividade do universo de estudantes italianos a partir de duas variáveis predeterminadas: 1 ) número de escolas por localização geográfica; 2) número de estudantes matriculados no $2^{\circ}$ ano do Ensino Secundário II.

As escolas que participaram da pesquisa foram selecionadas por meio de sorteio aleatório, realizado com auxílio da identificação de números sorteados pela loteria federal do dia 23 de novembro de 2013, isto é, foi atribuída uma base numérica para a lista de escolas do país, divulgada pelo Ministério de Educação Italiano, e, a partir do sorteio da loteria federal, 100 escolas foram convidadas a participar do projeto de pesquisa. Entretanto, houve 14 recusas, substituídas mediante novo sorteio, com base nas extrações numéricas da loteria federal dos dias 10 de dezembro de 2013 e 21 de janeiro de 2014, que resultou no envio de questionários para 103 escolas, das quais se obteve o retorno de 99 instituições espalhadas por todo o território italiano. A composição final da amostra italiana foi: 920 estudantes do Noroeste (26,3\%); 838 do Sul (23,9\%); 771 do Nordeste (22\%); 556 do Centro (15,9\%) e 418 das Ilhas (11,9\%).

A coleta de dados aconteceu entre os meses de março e maio de 2014. Houve a participação de 3.503 estudantes, sendo 52\% de meninas, e na faixa etária entre 15 e 16 $\operatorname{anos}(77,3 \%)$.

\section{Instrumento de coleta de dados}

O questionário Barômetro procura mensurar percepções, motivações, interesses e opiniões de jovens sobre Ciência, tecnologia, questões ambientais e temas científicos, particularmente a teoria da evolução biológica. Ele foi estruturado a partir da redução de itens do instrumento Relevanceof Science Education (ROSE), com questões no formato de escalas do tipo Likert de 4 pontos, múltipla escolha, e verdadeiro ou falso. O presente trabalho ocupou-se principalmente das seções que verificaram as relações dos jovens com 
a religião e com a evolução humana. Na seção religião, buscou-se verificar a frequência com que os estudantes consideram ter uma religião. Em seguida, os estudantes deveriam assinalar a congregação religiosa a que eram adeptos (formato múltipla escolha), sendo a questão adequada às denominações religiosas de cada país.

No questionário aplicado no Brasil, os estudantes que possuíssem religião deveriam informar o vínculo institucional, entre as seguintes igrejas ou cultos religiosos: Católicas: romana e ortodoxa; Evangélicas de missão: luterana, presbiteriana, batista, adventista; Evangélicas de origem pentecostal: Assembleia de Deus, Congregação Cristã do Brasil, Internacional da Graça de Deus, Mundial do Poder de Deus, Universal do Reino de Deus; Outras religiões: testemunha de Jeová, judaica, budista, umbanda, candomblé, espírita kardecista. Além disso, havia a opção Outra, seguida da opção Em aberto para os casos em que a igreja ou culto religioso do pesquisado(a) não estivesse disponível entre os itens elencados. Houve alta variedade de credos religiosos entre os jovens pesquisados, desta forma, para facilitar as análises estatísticas, os grupos identificados foram reagrupados em: católicos, evangélicos de missão, evangélicos pentecostais, outras religiões e sem religião.

No questionário aplicado na Itália, o(a) jovem deveria assinalar, entre os seguintes itens: 1) sim, uma religião cristã católica; 2) sim, uma religião cristã não católica (ortodoxa, luterana, valdense...); 3) sim, outras religiões (hebraica, budista, islâmica); 4) sim, uma filosofia Nova Era; 5) não, não acredito em nenhuma religião ou filosofia transcendental. As variáveis citadas foram consideradas, tendo em vista as características culturais da Itália, país predominantemente católico, com reconhecida diversidade de expressões religiosas, porém não tão marcante como no Brasil, segundo sugerem os pesquisadores italianos (Giuseppe Pellegrini, informação pessoal).

Ainda nesta seção, os estudantes brasileiros e italianos deveriam, em uma escala do tipo Likert de 4 pontos, identificar a concordância com frases sobre a proximidade com a religião: 1) Os conhecimentos religiosos são úteis na minha vida; 2) Minha religião afetaria minha escolha de uma carreira ou um emprego; 3) Minha religião contradiz alguns conteúdos das aulas de Ciências.

$\mathrm{Na}$ seção sobre a origem do homem, foram elencadas algumas interpretações presentes na sociedade, assim como a explicação científica. A questão foi estruturada no formato de múltipla escolha e a opção indicada pelos jovens deveria representar o que lhes parecia mais aceitável no que se refere à presença do homem no meio ambiente. Assim, uma das opções explica a origem do homem a partir da interpretação científica "Uma evolução gradual devido às variações genéticas, aleatórias e seleção natural" e três opções representam interpretações socioculturais.

Entre as opções socioculturais, há uma que se aproxima das ideias de planejamento sobrenatural: "Um plano divino que planejou e guiou a evolução biológica"; uma opção que representa a ideia de progresso natural: "Uma progressão natural guiada para atingir a perfeição - o homem"; e, ainda, uma afirmação para representar a interpretação da criação sobrenatural: "Da criação divina, diretamente com as formas que conhecemos 
atualmente". Por último, há a opção "Não saberia dizer".

\section{Análise dos dados}

Como mencionado no início, os dados foram analisados com auxílio do Software Statistical Package for Social Science (SPSS) - versão 18.0. Os dados brasileiros e italianos foram explorados a partir de uma análise comparativa, apontando inicialmente os dados descritivos representados por números absolutos, relativos e médias/desvios-padrão para cada variável referente à relação dos jovens com a religião e a origem do homem. Para verificar as diferenças entre as distribuições de frequências atingidas pelo Brasil e pela Itália, nas questões analisadas, foram utilizados os testes: Qui-quadrado, MannWhitney e Kruskal-Wallis, seguidos das comparações múltiplas entre grupos mediante teste de Tukey.

\section{Resultados e Discussões}

\section{Religião para os jovens brasileiros e italianos}

Quanto à variedade de credos religiosos, na Itália observa-se a seguinte distribuição de respostas, por sexo (Figura 1).

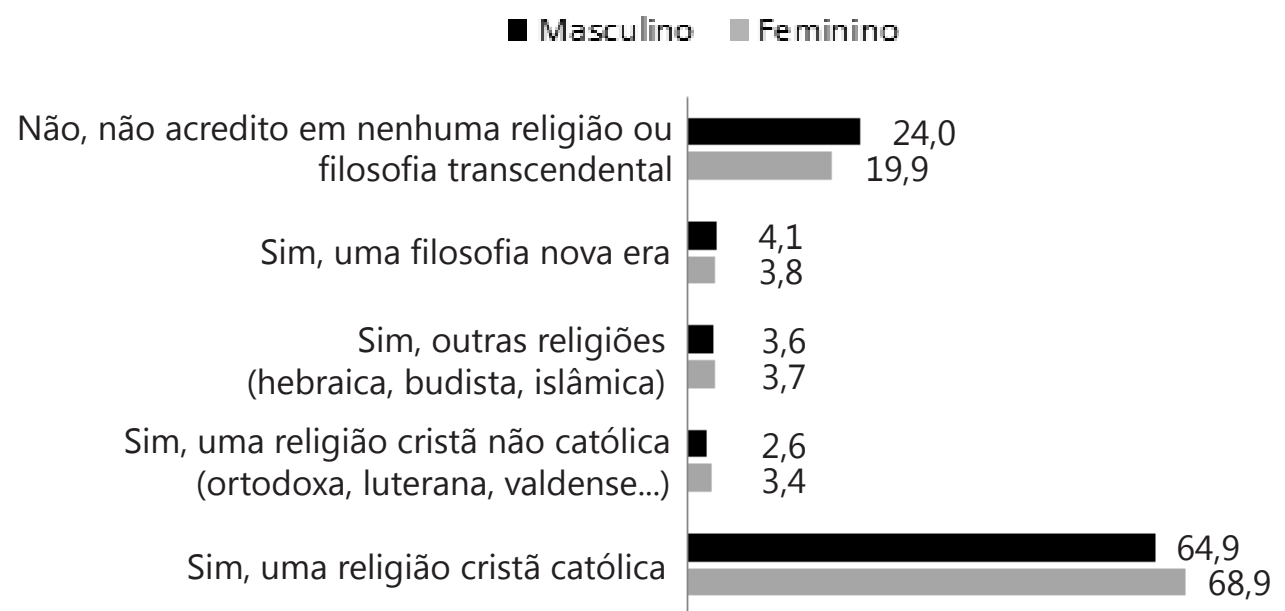

Figura 1. Distribuição da amostra italiana quanto à opção religiosa ou filosófica, por sexo. $(n=3.503)$

A maioria dos jovens italianos declarou-se adepta ao catolicismo, seguida por aqueles que optaram por: Não, não acredito em nenhuma religião ou filosofia transcendental. De maneira geral, os menores índices foram identificados nos grupos religiosos: filosofia Nova Era; religiões cristãs não católicas; outras religiões. De acordo com Davie (2010), nos países europeus, há uma forte predominância de instituições religiosas cristãs, com importante valor simbólico para a população. Mas isto não significa que, em algumas partes da Europa (nomeadamente as cidades maiores), já não se perceba indicadores da crescente diversidade religiosa, mas os legados do passado permanecem profundamente enraizados no ambiente físico e cultural de vários países 
europeus.

Quando comparados os resultados de ambas as pesquisas, observa-se que o percentual de católicos na Itália é mais alto, enquanto no Brasil há maior diversidade de credos religiosos, de modo que há dois grupos protestantes distintos e com percentuais altos. Além disso, a presença de outras religiões entre os brasileiros também é mais frequente (Figura 2).

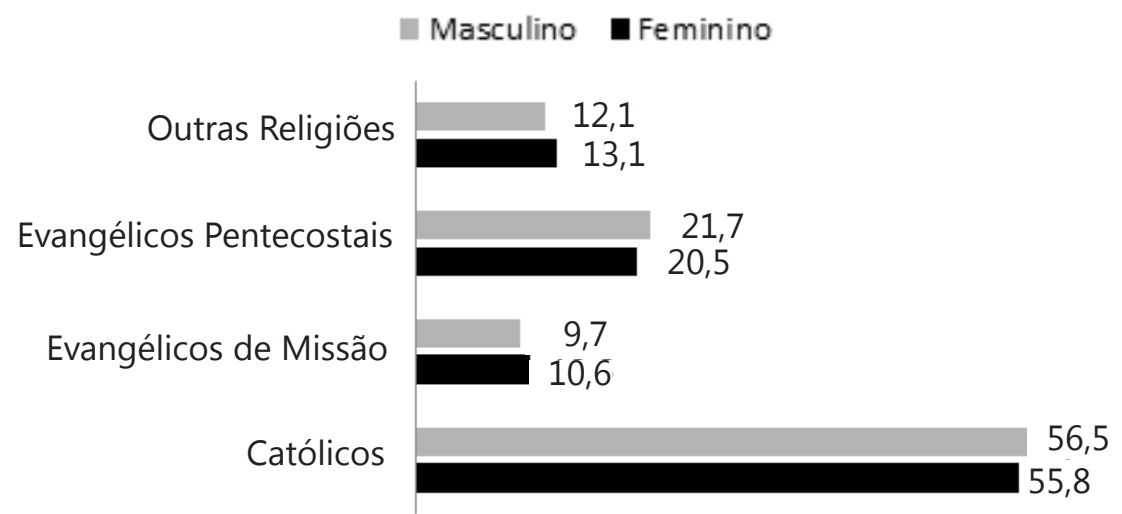

Figura 2. Distribuição da amostra brasileira quanto à opção religiosa ou filosófica, por sexo. $(n=2404)$

Quanto aos percentuais de jovens que se declararam adeptos e não adeptos a uma religião, na Itália, há maior frequência do grupo sem religião: 19,9\% de meninas e $24,1 \%$ de meninos; enquanto no Brasil, a frequência é 9,6\% de meninas e $14,3 \%$ de meninos. Brasil e Itália são países de maioria católica, não necessariamente hegemônica, visto que há uma crescente manifestação de grupos religiosos cristãos não católicos, particularmente no Brasil. Em ambos os países também foram identificados jovens que se autodeclaram sem religião, geralmente, representados por indivíduos que compõem um repertório particular de crenças e práticas variadas, mas que não se identificam com qualquer instituição religiosa, e também por grupos de ateus e agnósticos (Almeida; Monteiro, 2001).

A presença de grupos sem religião, principalmente no Brasil, não aponta fundamentalmente um processo de secularização, de maneira geral, observa-se que os indivíduos não se identificam com uma instituição religiosa, mas mantêm interesses religiosos. Para Novaes (2004, p. 328), esse segmento possui "um certo consumo de bens religiosos sem as clássicas mediações institucionais como um estado provisório (entre adesões) ou como uma alternativa de vida e de expressão cultural".

De acordo com Bruce (2010), nos países ocidentais, destaca-se o ressurgimento do interesse religioso, pois, quando uma tradição religiosa declina, surge outra para preencher a lacuna. Por exemplo, conforme os católicos declinam, surgem novas ondas religiosas, como os movimentos pentecostais da década de 1920, os carismáticos em 1960 e os novos movimentos espirituais da Nova Era dos anos 1990, entre outros movimentos que exemplificam a forte relação do ser humano com a religiosidade. 
Quanto à religião nos países europeus, Davie (2010) afirma que, para entender o lugar da religião na Europa, é importante considerar o papel das igrejas na cultura europeia e a consciência de que essas instituições religiosas desempenharam uma importante função em determinados momentos históricos de grande parte da população; isto é, a religião enquanto possibilidade de escolha, ao invés de um modelo de obrigação ou dever; a chegada de pessoas de diferentes partes do mundo na Europa, com diferentes aspirações religiosas; e a percepção de que os padrões de vida religiosa na Europa são diferentes dos de várias partes do mundo.

Quando Davie (2010, p. 174) menciona que os padrões religiosos europeus são distintos de outras partes do mundo, destaca "o que a Europa não é", pois a religião na Europa (ainda) não é um mercado religioso vibrante como na América, pois não se observa um crescimento exponencial de novos grupos cristãos, como acontece com os pentecostais no hemisfério sul, bem como não tem sido observado o crescimento de outros grupos religiosos, embora nos países europeus se verifique cada vez a presença desses grupos.

Para verificar a relação dos jovens italianos com a religião, foram testadas afirmações que remetem à atribuição de valor aos conhecimentos religiosos no cotidiano, e no reconhecimento da religião nas suas escolhas, como nas pretensões profissionais. Além disso, examinou-se a percepção do jovem quanto a possíveis incompatibilidades entre o credo religioso e o que é ensinado nas aulas de Ciências. Na Tabela 1, são apresentadas as médias atingidas pelos italianos para os itens, por sexo.

Tabela 1. Média (desvio-padrão) e teste de Mann-Whithey para proximidade dos jovens italianos à religião, por sexo. $(\mathrm{n}=3503)$

\begin{tabular}{lccc}
\hline \multirow{2}{*}{ Respostas } & \multicolumn{2}{c}{ Média (desvio-padrão) } & \multirow{2}{*}{ p-valor } \\
\cline { 2 - 3 } & $\mathrm{F}$ & $\mathrm{M}$ & \\
\hline Os conhecimentos religiosos são úteis na minha vida & $2,28(2,4)$ & $2,42(4,8)$ & 0,231 \\
\hline $\begin{array}{l}\text { Minha religião afetaria minha escolha de uma carreira ou um } \\
\text { emprego }\end{array}$ & $1,52(0,7)$ & $1,70(3,5)$ & $\mathbf{0 , 0 1 1}$ \\
\hline $\begin{array}{l}\text { Minha religião contradiz alguns conteúdos das aulas de } \\
\text { Ciências }\end{array}$ & $2,17(2,5)$ & $2,59(6,8)$ & 0,993 \\
\hline
\end{tabular}

Quando comparadas as respostas por sexo, percebe-se que os jovens italianos parecem concordar que a religião é um componente importante no seu cotidiano. Houve menor concordância no item sobre a influência da religião na escolha profissional, sendo que meninas apresentaram a menor média $(1,52 \pm 0,7)$. Quanto à percepção de que a religião contradiz conteúdos científicos, houve concordância entre os jovens: média de $2,17 \pm 2,5$ para meninas, e de $2,59 \pm 6,8$ para meninos.

No Brasil, as meninas consideram com maior frequência a religião como empreendimento útil no cotidiano. Tanto as meninas como os meninos concordam que há algumas contradições entre a religião e Ciência e discordam que preceitos religiosos 
possam influenciar na escolha de uma carreira (Tabela 2).

Tabela 2. Média (desvio-padrão) e teste de Mann-Whithey para proximidade dos jovens brasileiros à religião, por sexo. $(\mathrm{n}=2404)$

\begin{tabular}{lccc}
\hline \multirow{2}{*}{ Respostas } & \multicolumn{2}{c}{ Média (desvio-padrão) } & \multirow{2}{*}{ p-valor } \\
\cline { 2 - 3 } & $\mathrm{F}$ & $\mathrm{M}$ & \\
\hline Os conhecimentos religiosos são úteis na minha vida & $3,39(0,93)$ & $3,10(1,09)$ & $\mathbf{0 , 0 0 4}$ \\
\hline $\begin{array}{l}\text { Minha religião afetaria minha escolha de uma carreira ou } \\
\text { um emprego }\end{array}$ & $1,51(0,97)$ & $1,54(0,98)$ & 0,249 \\
\hline $\begin{array}{l}\text { Minha religião contradiz alguns conteúdos das aulas de } \\
\text { Ciências }\end{array}$ & $2,29(1,26)$ & $2,27(1,26)$ & 0,602 \\
\hline
\end{tabular}

De modo geral, os brasileiros mostraram mais proximidade com a religião; as meninas brasileiras atribuem maior valor aos ensinamentos religiosos para sua vida, se comparadas às médias dos demais jovens. Quanto ao item que se refere à religião como um componente que contradiz os conhecimentos científicos, a média mais alta foi atingida por meninos italianos (Figura 3).

Brasil Itália

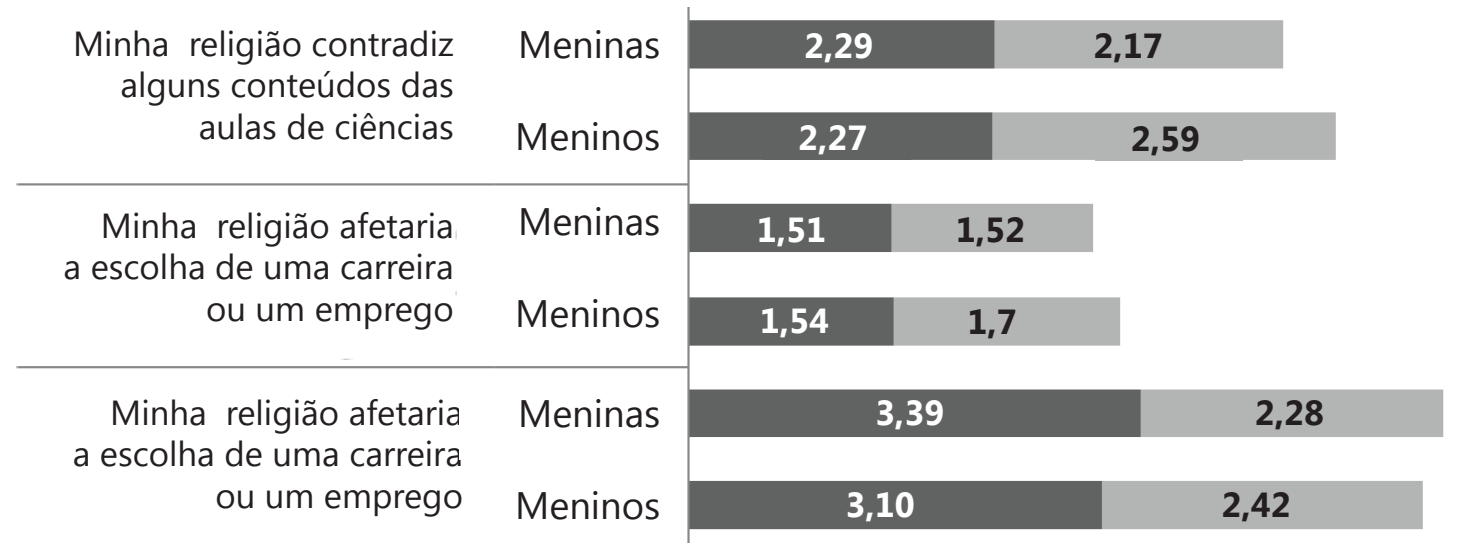

p-valor: 0,002

Figura 3. Distribuição das amostras brasileiras e italianas quanto à proximidade com a religião, por sexo. $(\mathrm{n}=3503)$

Houve o interesse por verificar a diversidade de respostas para a variável "grupos religiosos". Na Itália, os jovens cristãos não católicos concordaram com maior frequência diante dos itens que afirmam que a religião é um componente importante $(3,60 \pm 9,6)$, em seguida há a média dos jovens de outras religiões $(2,78 \pm 1,1)$ e a dos jovens católicos $(2,58 \pm 3,6)$. Quanto ao item que trata da religião como um empreendimento que poderia influenciar na escolha de uma profissão, os jovens cristãos não católicos pontuaram com maior frequência $(2,93 \pm 9,7)$, seguidos dos jovens de outras religiões $(2,06 \pm 1,1)$ (Figura 4). 
—Cristấo católico $\quad$ Cristão não católico $\quad$ Outras religiões
— Filosofia nova era $\quad$ 'Sem religião

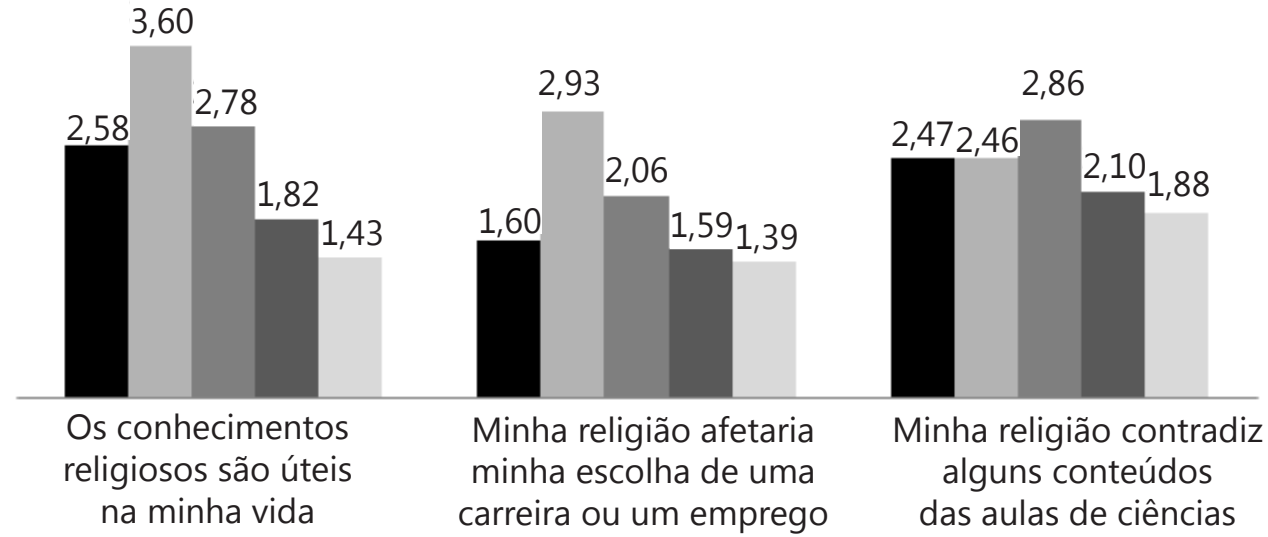

p-valor: 0,000

Figura 4. Distribuição da amostra italiana quanto à proximidade com a religião, por grupos religiosos. $(\mathrm{n}=3503)$

Na afirmação "minha religião contradiz alguns conteúdos das aulas de Ciências", os jovens de outras religiões apresentaram média mais alta de concordância $(2,86 \pm 1,2)$,

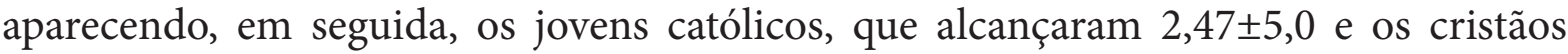

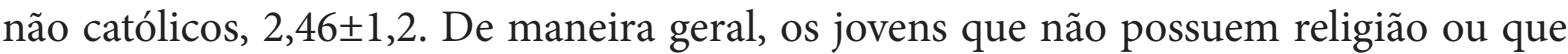
são adeptos de filosofias como a Nova Era apresentaram médias de concordância mais baixas. Os resultados encontrados sobre as opiniões dos jovens sem religião sugerem que alguns, embora se reconheçam sem vínculos institucionais, apresentam alguns traços de religiosidade nas suas respostas. De acordo com Almeida e Monteiro (2001), a não filiação não significa necessariamente ausência de religiosidade.

Quando comparados os resultados encontrados para os grupos religiosos brasileiros, observa-se que a oscilação de médias entre os grupos é menor do que a identificada na Itália, principalmente na atribuição de valor à religião ao cotidiano; entretanto, os jovens adeptos aos grupos protestantes demonstraram maior concordância

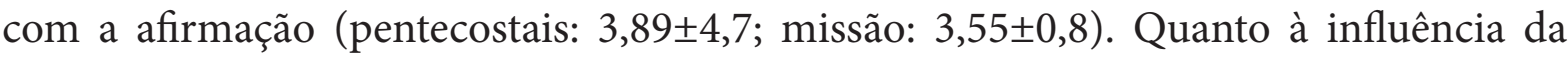
religião na escolha de uma carreira, a média mais alta foi atingida por evangélicos de missão $(2,00 \pm 1,2)$. Sobre a percepção de que a religião e os conteúdos científicos são contraditórios, os jovens evangélicos pentecostais e os de missão concordaram com maior frequência, com 2,92 $\pm 4,9$ e 2,87 $\pm 1,1$, respectivamente (Figura 5).

Nos dois países, observa-se que os jovens adeptos a religiões cristãs e não católicos apresentam maior concordância diante dos itens que atribuem valor à religião no cotidiano e na possível influência na escolha profissional. Também os jovens cristãos não católicos italianos, evangélicos de missão e pentecostais brasileiros percebem que a religião contradiz alguns conceitos científicos com maior frequência. Além disso, entre os diferentes grupos religiosos italianos há maior reconhecimento de que a religião 
poderia afetar a escolha de uma profissão ou um emprego.

- Católicos
-Outras Religiões

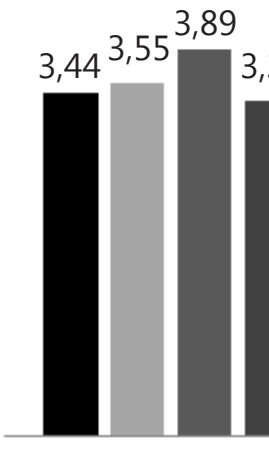

Os conhecimentos religiosos são úteis na minha vida

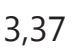

Evangélicos de missão

Sem Religião

p-valor: 0,002

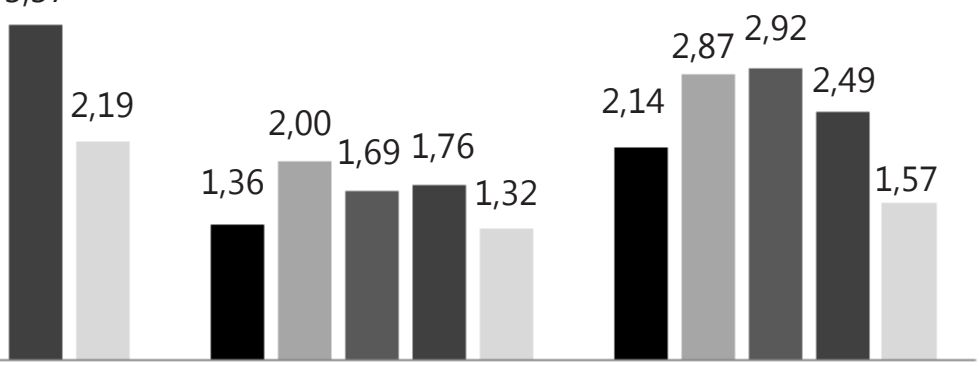

Minha religião afetaria minha escolha de uma carreira ou emprego
Evangélicos Pentecostais

Minha religião contradiz alguns conteúdos das aulas de ciências

Figura 5. Distribuição da amostra brasileira quanto à proximidade com a religião, por grupos religiosos. $(n=2404)$

Os estudantes brasileiros e italianos consideram relevantes os valores religiosos, de maneira que alguns entendem que a religião é um componente útil para si e influencia suas escolhas profissionais. Existe a percepção entre os jovens de que os conceitos científicos divergem dos conhecimentos religiosos; os que concordaram com maior frequência com a afirmação de que os conhecimentos religiosos são úteis no cotidiano apresentaram maior média no item referente à contradição entre Ciência e religião. De maneira geral, infere-se que os grupos religiosos evangélicos dos dois países apresentam maior proximidade dos preceitos religiosos e do conhecimento dos fundamentos de sua crença.

Assim, possivelmente os mesmos conhecem mais a religião a que são adeptos, percebendo com maior frequência possíveis contradições entre religião e Ciência. Entretanto, os resultados encontrados não possibilitaram verificar como os jovens convivem com essa percepção, se de uma maneira conflitante ou pacífica. Por outro lado, as análises da relação dos jovens com a teoria da evolução biológica podem contribuir para uma melhor compreensão de como os jovens que percebem essas contradições se relacionam com temas científicos.

\section{Origem humana: opiniões de jovens brasileiros e italianos}

Os jovens brasileiros e italianos responderam sobre como o homem poderia ter surgido na Terra. Houve diferença significativa entre as respostas dos dois países, em uma margem de 5\%. Na Itália, as explicações mais frequentes atribuídas à origem humana foram: científica $(45,7 \%)$, não souberam responder $(20,4 \%)$ e a explicação por 
progressão natural (19,4\%). Em menor incidência estão: ideia de planejamento divino $(8,7 \%)$ e ideia de criação divina com as formas atuais (5\%).

Os resultados brasileiros apontam que os jovens que não souberam responder $\mathrm{e}$ os que atribuem a ideia de criação divina à origem humana apresentam maior frequência e atingiram ambos 30,6\%. Em seguida, estão os jovens que assinalaram a explicação científica $(21,8 \%)$, e os menores percentuais foram atingidos nas opções referentes às ideias de planejamento divino $(11,3 \%)$ e de progressão natural $(5,6 \%)$.

Esses resultados iniciais sugerem claramente que os jovens italianos estão mais dispostos a reconhecer a validade da explicação científica para a origem do homem, enquanto os jovens brasileiros não souberam responder, e, quando optaram por uma explicação para a própria origem, a criação divina figurou como opção mais plausível.

Em ambas as amostras houve diferença significativa nas respostas para a origem humana, por sexo (p-valor 0,000). Especificamente na pesquisa italiana, as meninas apresentaram maior frequência na opção que explica a origem do homem por fenômenos naturais do que os meninos, e menor frequência nas opções que explicam a origem a partir da criação divina e acerca da progressão natural. Em contrapartida, as amostras apresentaram percentuais próximos quando o item afirma que a origem foi a partir do planejamento divino. Além disso, as meninas apontaram com maior frequência que não sabiam responder (Figura 6).

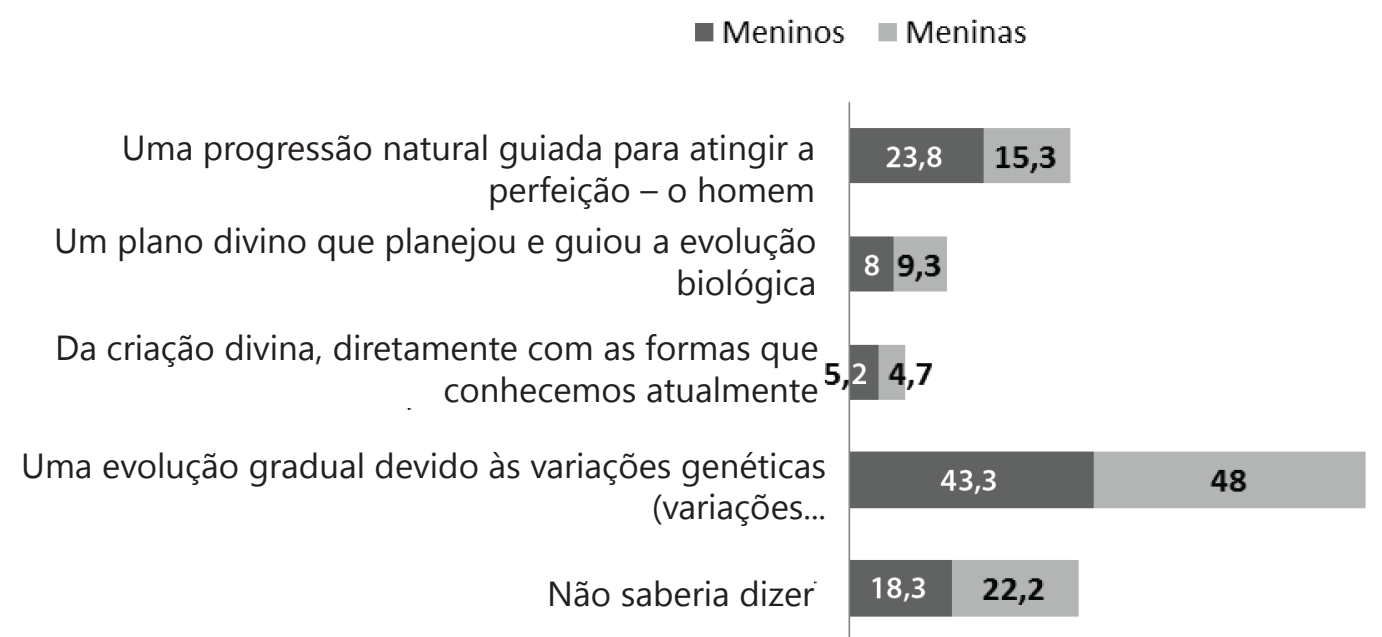

p-valor 0,000

Figura 6. Distribuição da amostra italiana quanto às opiniões acerca da origem humana, por sexo. $(\mathrm{n}=3503)$

Nos dados brasileiros, identificou-se que os meninos apontaram com maior frequência a explicação científica; e as meninas a criação divina. Os percentuais foram semelhantes tanto em relação à origem por planejamento divino como quando os jovens não souberam responder sobre o assunto. Na afirmação de que o homem se originou a partir de progressão natural, houve maior frequência por parte dos meninos (Figura 7).

Nos dados brasileiros, identificou-se que os meninos apontaram com maior 
frequência a explicação científica; e as meninas a criação divina. Os percentuais foram semelhantes tanto em relação à origem por planejamento divino como quando os jovens não souberam responder sobre o assunto. Na afirmação de que o homem se originou a partir de progressão natural, houve maior frequência por parte dos meninos (Figura 7).

- Masculino Feminino

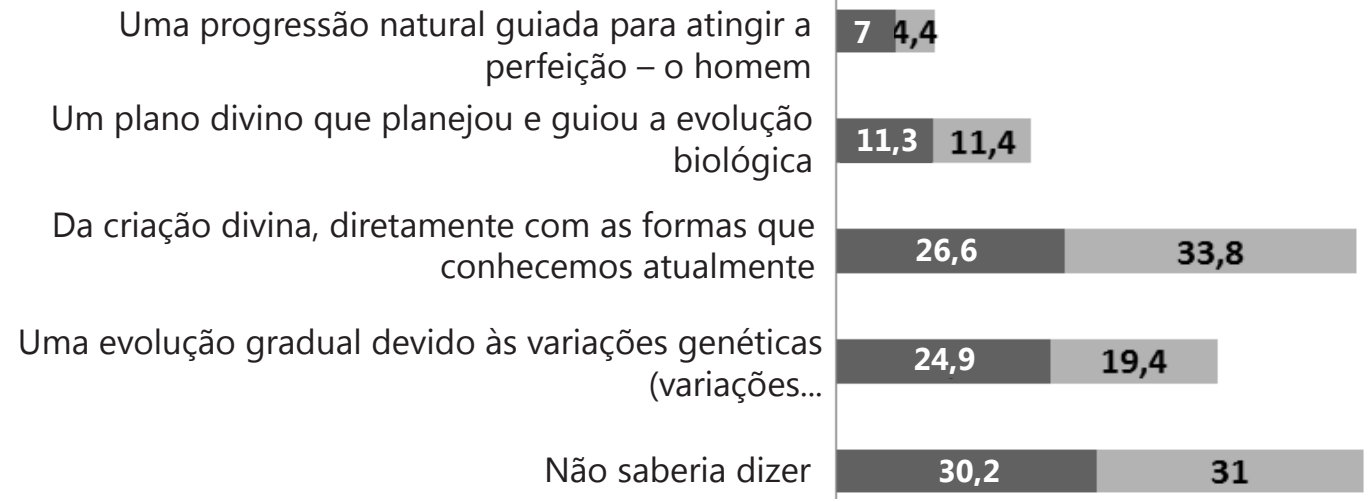

p-valor 0,000

Figura 7. Distribuição da amostra brasileira quanto às opiniões acerca da origem humana, por sexo. $(n=2404)$

$\mathrm{Na}$ Itália, as meninas parecem mais propensas a reconhecer a origem humana a partir de fenômenos naturais, ao passo que os meninos apresentaram percentuais mais altos nos itens que incluem intervenção sobrenatural na origem do homem, exceto no item referente ao planejamento divino.

A mesma tendência foi identificada no Brasil. No entanto, os meninos reconheceram com maior frequência a ideia científica para a origem do homem, e as meninas optaram por explicações de cunho religioso para a própria origem. É importante destacar ainda o alto índice de meninos e meninas que não souberam responder sobre o assunto.

Quanto à religião, examinou-se a variedade de respostas por grupos religiosos, uma vez que a ideia da origem humana apresenta diferentes versões dentro de cada cultura religiosa e, possivelmente, o posicionamento do estudante acerca da própria origem pode ser influenciado por crenças pessoais. Foram verificadas as respostas dos jovens italianos com e sem religião, e houve diferença significativa, em uma margem de $5 \%$ (Figura 8).

Os jovens italianos sem religião apresentaram percentuais mais altos na explicação científica para a origem humana. Os estudantes com religião que reconheceram o planejamento, a criação divina e não souberam responder acerca da origem do homem possuem religião e atingiram 10,7\%, 6,0\% e 21,9\%, respectivamente. Quanto à progressão natural, não houve diferença nas respostas dos jovens com e sem religião.

Nas respostas dos jovens brasileiros que possuem religião e os sem religião, houve diferença significativa em uma margem de $5 \%$. Os sem religião pontuaram com maior 
frequência a explicação científica; os que possuem religião apontaram que o homem teve origem com a criação divina e por planejamento divino. Não houve diferença significativa nas respostas dos jovens que reconheceram a validade da ideia de progressão natural e os estudantes que não souberam responder (Figura 9).

\section{- Possui religião Sem religião}

Não saberia dizer

\section{$21,914,3$}

Da criação divina, diretamente com as formas que conhecemos atualmente 6,0 1,5

Uma progressão natural guiada para atingir a perfeição - o homem

Um plàno divino qüe planejou è guiou a evolução biológica

Uma evolução gradual devido às variações aleatórias e seleção natural

\section{$19,220,0$}

$10,72,0$

\section{1,7 61,2}

p-valor 0,000

Figura 8. Distribuição da amostra italiana acerca das opiniões sobre a origem humana, por grupos (possui religião e sem religião). $(n=3503)$.

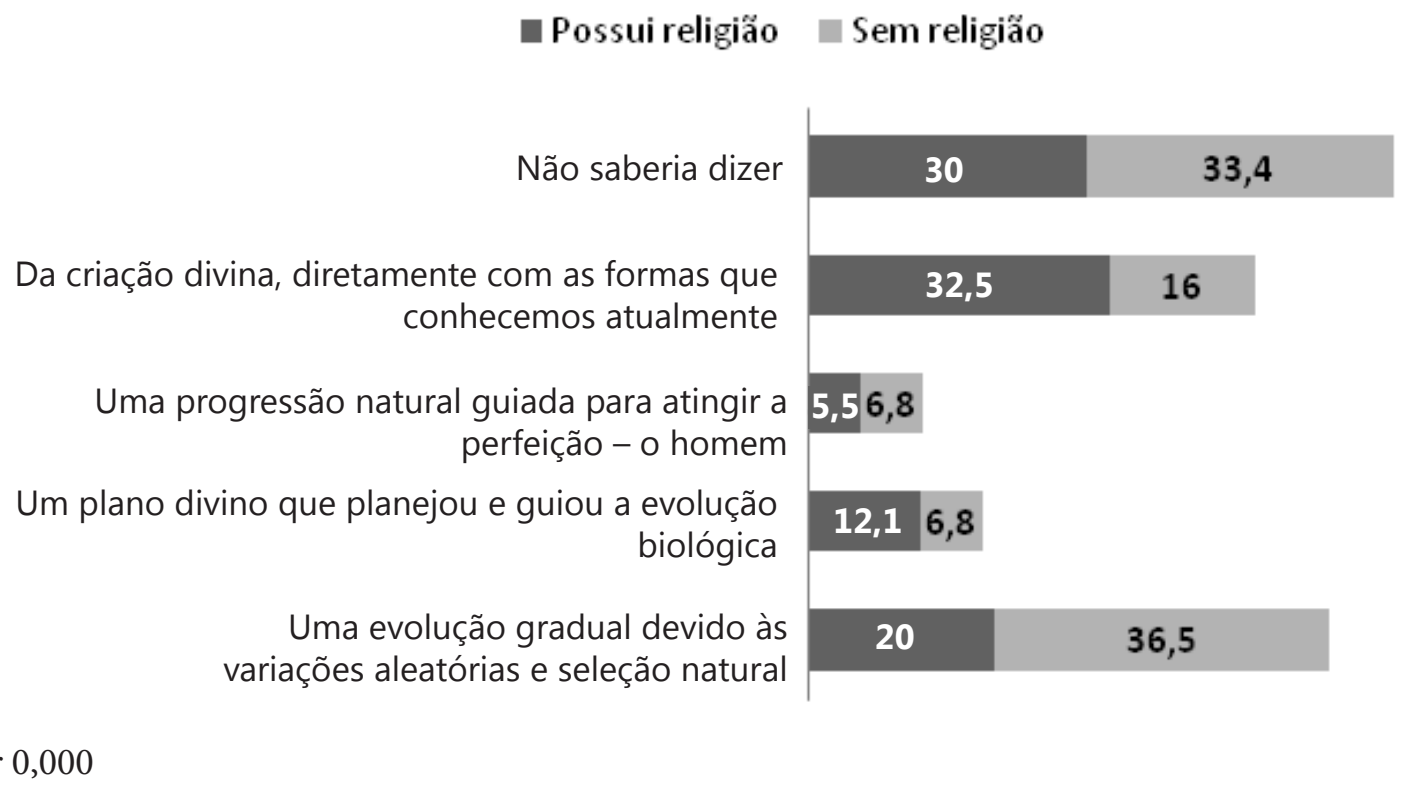

Figura 9. Distribuição da amostra brasileira acerca das opiniões sobre a origem humana, por grupos que possuem religião e sem religião. $(n=2404)$

Os estudantes que possuem religião optaram relativamente menos pela explicação científica para a própria origem; em contrapartida, apresentaram maior escolha pelas opções que remetem a explicações sociais e culturais para a origem humana. Além disso, como no caso da 
Itália, maiores foram os percentuais na opção "Não saberia dizer".

No entanto, os dados revelam que os jovens brasileiros que possuem religião recusam com maior intensidade a ideia científica para a origem do homem e optaram com maior frequência pela criação divina; em seguida, destacam-se os jovens que não souberam responder.

Quanto às respostas dos estudantes por grupos religiosos, observa-se que houve diferença significativa em uma margem de $5 \%$ nos dois países (Tabelas 3 e 4 ).

Tabela 3. Distribuição da amostra italiana quanto às opiniões sobre origem humana, por grupos religiosos. $(\mathrm{n}=3503)$

\begin{tabular}{|c|c|c|c|c|}
\hline & $\begin{array}{l}\text { Cristão } \\
\text { católico }\end{array}$ & $\begin{array}{l}\text { Cristão não } \\
\text { católico }\end{array}$ & $\begin{array}{r}\text { Outras } \\
\text { religiões }\end{array}$ & $\begin{array}{r}\text { Filosofia } \\
\text { Nova Era }\end{array}$ \\
\hline & \multicolumn{4}{|c|}{$\%$} \\
\hline $\begin{array}{l}\text { Uma evolução gradual devido às variações } \\
\text { aleatórias e seleção natural }\end{array}$ & 41,9 & 32,3 & 30,4 & 52,6 \\
\hline $\begin{array}{l}\text { Um plano divino que planejou e guiou a } \\
\text { evolução biológica }\end{array}$ & 10,9 & 15,2 & 9,6 & 4,5 \\
\hline $\begin{array}{l}\text { Uma progressão natural guiada para atingir a } \\
\text { perfeição - o homem }\end{array}$ & 19,3 & 18,2 & 16,8 & 20,3 \\
\hline $\begin{array}{l}\text { Da criação divina, diretamente com as } \\
\text { formas que conhecemos atualmente }\end{array}$ & 5,2 & 16,2 & 14,4 & 5,3 \\
\hline Não saberia dizer & 22,0 & 17,2 & 28,0 & 17,3 \\
\hline
\end{tabular}

p-valor 0,000

Tabela 4. Distribuição da amostra brasileira quanto às opiniões sobre origem humana, por grupos religiosos. $(\mathrm{n}=2404)$

\begin{tabular}{|c|c|c|c|c|}
\hline & Católicos & $\begin{array}{l}\text { Evangélicos } \\
\text { de missão }\end{array}$ & $\begin{array}{l}\text { Evangélicos } \\
\text { pentecostais }\end{array}$ & $\begin{array}{r}\text { Outras } \\
\text { religiões }\end{array}$ \\
\hline & \multicolumn{4}{|c|}{$\%$} \\
\hline $\begin{array}{l}\text { Uma evolução gradual devido às variações } \\
\text { genéticas e seleção natural }\end{array}$ & 24,9 & 13,2 & 12,2 & 16,9 \\
\hline $\begin{array}{l}\text { Um plano divino que planejou e guiou a } \\
\text { evolução biológica }\end{array}$ & 10,0 & 16,8 & 15,7 & 11,7 \\
\hline $\begin{array}{l}\text { Uma progressão natural guiada para atingir } \\
\text { a perfeição - o homem }\end{array}$ & 6,4 & 3,6 & 5,0 & 3,6 \\
\hline $\begin{array}{l}\text { Da criação divina, diretamente com as } \\
\text { formas que conhecemos atualmente }\end{array}$ & 25,7 & 44,2 & 41,1 & 37,9 \\
\hline Não saberia dizer & 33,1 & 22,3 & 25,9 & 29,8 \\
\hline
\end{tabular}

p-valor 0,000 
Nas respostas dos jovens italianos, observa-se que os cristãos não católicos e de outras religiões apresentaram percentuais mais baixos para a explicação científica sobre a origem do homem $(32,3 \%$ e $30,4 \%$, respectivamente). Os estudantes que apresentaram maior percentual para explicação científica foram os ligados à filosofia Nova Era.

Quanto ao item sobre o planejamento divino, destacaram-se as respostas dos jovens cristãos não católicos $(15,2 \%)$ e, no constructo sobre a progressão natural, as dos jovens adeptos à filosofia Nova Era (20,3\%). A alternativa sobre a criação divina foi assinalada com maior frequência pelos cristãos não católicos $(16,2 \%)$ e por outras religiões $(14,4 \%)$. Os jovens que não souberam responder com maior frequência foram os católicos (22\%) e de outras religiões (28\%).

Os jovens brasileiros que apresentaram maior percentual na explicação científica foram os católicos (24,9\%); os menores percentuais foram pontuados pelos evangélicos de missão (13,2\%) e evangélicos pentecostais (12,2\%). Entretanto, os evangélicos apresentaram percentuais mais altos nas opções que explicam a origem humana a partir do planejamento (evangélicos de missão: 16,8\%; pentecostais: 15,7\%) e por criação divina (evangélicos de missão: 44,2\%; pentecostais: 41,1\%). O item sobre progressão natural foi assinalado com maior frequência pelos católicos (6,4\%). Os estudantes que não souberam responder foram os católicos $(33,1 \%)$ e os adeptos de outras religiões $(29,8 \%)$.

Os resultados encontrados confirmam as impressões anteriores de que determinados grupos religiosos concordam com menor frequência acerca da veracidade da teoria evolutiva e, particularmente, no que se refere à evolução humana, em que as diferenças de respostas dos jovens parecem mais evidentes.

Os estudantes italianos cristãos não católicos e de outras religiões, bem como os evangélicos brasileiros (missão e pentecostais) aceitam com menor frequência explicações científicas para a origem do homem. Embora haja maior conhecimento entre os jovens italianos sobre a teoria evolutiva, os preceitos religiosos influenciam suas respostas, mesmo que em menor proporção do que observado nas respostas dos brasileiros.

Quanto à aceitação sobre a evolução humana, os jovens italianos estão mais dispostos a assumir uma posição científica para a própria origem, ao passo que as influências socioculturais foram mais intensas nas respostas dos jovens brasileiros. No Brasil, identificou-se o baixo conhecimento acerca da história do homem na Terra nas demais seções disponíveis no questionário (dados detalhados disponíveis em Oliveira, 2015). Associado a crenças religiosas, observa-se que a maioria, principalmente as meninas e jovens evangélicos, adota a explicação da origem do homem a partir da criação divina.

Ao analisar as concepções de estudantes do norte da Itália sobre registros fósseis, Bizzo (2011) verificou que esses demonstram ter amplo conhecimento dos períodos geológicos. Além disso, nas respostas dos jovens, não foram identificadas interpretações que envolvessem explicações sobrenaturais. Bizzo (2011) destaca que entre os estudantes 
italianos não houve negação de crenças religiosas, mas uma consideração sobre os fenômenos naturais a partir de explicações científicas. Esses resultados são semelhantes aos da presente pesquisa, pois os jovens italianos assumem com maior frequência o discurso científico para explicar a origem do homem.

A dimensão religiosa demonstrou-se uma variável relevante, uma vez que para alguns estudantes dos dois países adotar uma religião e identificar-se como parte de um grupo religioso faz com que explicações religiosas para a origem do homem tenham uma grande dimensão na visão de mundo dos mesmos. Se existem diferentes maneiras de explicar fenômenos da natureza, então, há possibilidades de que algumas pessoas rejeitem algumas dessas explicações e, entre essas, podem ser as explicações oferecidas pela Ciência ocidental (Cobern; Loving, 2001).

Os resultados dos questionários na Itália sugerem a influência da religião nas opiniões de uma pequena parcela dos jovens inquiridos. No Brasil, além de influências religiosas, é possível falar em problemas de conhecimento da teoria evolutiva. Os dados apontam que os estudantes brasileiros não possuem conhecimento adequado para responder sobre os assuntos elencados no questionário, havendo percentuais altos de jovens que não souberam responder sobre a origem do Homem. Nesse sentido, deve-se considerar que esses estudantes possivelmente se fazem outros questionamentos sobre o sentido da vida e sobre a origem das espécies.

Como dito, se os jovens brasileiros apresentam lacunas conceituais acerca da teoria evolutiva, então é razoável supor que a influência de visões ligadas ao meio sociocultural seja grande ao posicionar-se diante de fenômenos da natureza ou sobre sua própria origem. Nas próprias salas de aulas há heterogeneidade de opiniões, crenças, experiências, expectativas, valores e interesses, as quais nem sempre são evidentes no cotidiano.

A religião é uma expressão visível de uma visão de mundo, como um esqueleto das suposições cognitivas concretas (Cobern, 1991). As religiões monoteístas reconhecem a ação de um ser sobrenatural que conduziu a origem da vida, e isso pode ser percebido pela atração exercida pelas alternativas com categorias teológicas na representação do mundo. Também se supõe que as categorias biológicas sejam relativamente mais fracas na visão de mundo desses estudantes. Desta forma, é necessário supor que os valores culturais, os mitos e as ideologias necessariamente influenciam a aprendizagem das Ciências. Valores e crenças iminentes de um currículo de Ciências eurocêntrico muitas vezes entram em conflito com as crenças pessoais dos estudantes, podendo afastá-los da aprendizagem (Aikenhead, 2008).

Para alguns estudantes brasileiros o ser humano ainda aparece como resultado de uma criação especial e, para outros, como um tema desconhecido, o que sugere que a ideia de mudança gradual não é facilmente associada à evolução humana. Embora esses resultados pareçam associados a visões dogmáticas, em que os jovens religiosos têm menor adesão à teoria evolutiva, os altos percentuais de estudantes que não souberam responder sobre o tema chamam a atenção. Esses percentuais podem ser indicativos de 
um desejo de não expressar sua opinião, possivelmente devido a crenças religiosas. No entanto, isso tenderia a ser semelhante nas duas amostras. Assim, deve-se considerar a possibilidade de isto ser consequência da falta de conhecimento sobre a teoria evolutiva. Os estudantes não teriam recebido subsídios conceituais nas aulas de Ciências durante o Ensino Fundamental que pudessem contribuir para posicionamentos mais assertivos diante da teoria evolutiva, diferentemente dos jovens italianos que têm acesso à teoria evolutiva durante toda a escolarização.

De acordo com Berti, Toneatti e Rosati (2010), o ensino da teoria evolutiva na Itália é previsto desde o ensino primário. Desde 8 e 9 anos de idade, as crianças já conhecem alguns aspectos da teoria da evolução biológica, pois têm acesso a vários materiais acerca do tema. Além disso, a maioria dos livros didáticos traz a origem do universo, seguido do surgimento e da evolução da vida, desde o primeiro microorganismo aos mamíferos, acompanhado da apresentação da evolução humana, e conclui com a ascensão das primeiras civilizações. Desde o início do curso primário, as crianças italianas têm contato com os temas períodos geológicos e os principais eventos biológicos que ocorreram a partir do Big Bang até o aparecimento de Homo sapiens.

No Brasil, as Diretrizes Curriculares Nacionais para o Ensino Fundamental não fazem referência explícita à teoria da evolução biológica (Oliveira, Bizzo, 2011). A recente proposta da Base Nacional Comum Curricular remete apenas para os anos finais do ensino fundamental o estudo do tempo geológico, quando são trabalhadas as ideias evolutivas, começando pelas hipóteses sobre a origem da vida. Com isso, conteúdos com grande carga especulativa são apresentados junto ao estudo de fatos bem fundamentados, como o tempo geológico e o mecanismo da seleção natural, o que distorce o grau de incerteza da teoria evolutiva. Além disso, o estudo da diversidade biológica é enormemente reduzido.

Quanto ao tempo dedicado à teoria da evolução biológica e sua presença apenas no final da Educação Básica no currículo brasileiro, Bizzo e El-Hani (2009) consideram que a teoria evolutiva tem sido indevidamente tratada nas aulas de Biologia, o que tem favorecido resultados ineficazes. Muitos pesquisadores acreditam que a compreensão das bases da teoria evolutiva requer o entendimento da dimensão do tempo geológico, além do conhecimento da diversidade biológica. No ensino médio, recomenda-se incluir estudos sobre biologia molecular e genética, o que pode aprimorar, de maneira gradual e cumulativa, o entendimento da teoria.

De fato, Bizzo e El-Hani (2009) destacam que esses temas são relevantes no ensino da evolução biológica, mas existem algumas limitações ao apresentar a teoria evolutiva de maneira fragmentada, no final da educação básica. Além disso, a própria formação de professores em nível superior tem diminuído o tempo de estudo de aspectos geológicos e paleontológicos, incluindo a ideia de tempo geológico e macro evolução, os quais poderiam contribuir para a construção de espectros conceituais mais amplos de meio ambiente e suas dimensões de espaço e tempo.

As escolhas e decisões pedagógicas brasileiras parecem contribuir para o baixo 
conhecimento sobre a teoria evolutiva, o que, por conseguinte, faz com que estudantes da educação básica emitam opinião sobre fenômenos biológicos a partir de explicações socioculturais e religiosas. A falta de clareza sobre a origem humana parece resultado de um currículo escolar que tem negligenciado a teoria evolutiva enquanto eixo norteador das Ciências Biológicas e evitado discussões sobre a história humana na Terra.

Concomitante à falta de enfoque sobre a teoria evolutiva no Ensino Fundamental, a diversidade cultural do país se reflete na sala de aula na forma de diferentes crenças pessoais, e isso parece particularmente crítico para o ensino de Ciências, uma vez que, nessa diversidade, nem todos os alunos conseguem ser bem-sucedidos em Ciências (Cobern; Loving, 2008). Um tema como a teoria da evolução biológica possui relação com vários esquemas de visão de mundo, e é importante que os estudantes compreendam como essas questões se relacionam entre si, e que eles não se anulam, mas precisam ser adequadamente demarcadas conforme seus contextos específicos.

\section{Considerações Finais}

Os resultados encontrados na presente pesquisa apontam que as crenças pessoais e sobre a Ciência influenciam o que os jovens avaliam como evidências da evolução humana. Diante de estudos que apresentam que aspectos culturais podem interferir na maneira pela qual o estudante se relaciona com temas científicos, surge o desafio de favorecer, em sala de aula, situações didáticas que permitam a todos os alunos se envolverem com temas científicos sem o risco de estranhamentos.

Os estudantes experimentam perspectivas culturais diferentes nas aulas de Ciências, pois a maioria dos jovens não é familiarizada com conceitos e processos da Ciência no seu cotidiano. Especificamente, muitos estudantes atravessam as fronteiras culturais das subculturas de colegas e familiares às subculturas de ciências da escola em um ciclo de vida singular, no qual cada adolescente constrói progressivamente sua própria identidade. Diversos autores consideram ainda que alguns estudantes podem experimentar dificuldades ao ultrapassar a fronteira entre o conhecimento cultural e o científico (Donnelly; Kazempour; Amirshokoohi, 2009). Neste contexto, conhecer as opiniões e expectativas dos jovens sobre temas científicos seria um passo importante, pois a heterogeneidade de opiniões dos jovens em torno da evolução biológica e como as diferentes variáveis sociais atuam nestas relações nem sempre estão evidentes em sala de aula.

Os estudantes são capazes de orientar a sua própria aprendizagem, se provocados por recursos e métodos que contribuam para o cruzamento de fronteiras entre o seu mundo cotidiano para a cultura da Ciência (Hanley, Bennett, Ratcliffe, 2014). A abordagem didática de Aikenhead e Jegede (1999) propõe que, nos confrontos da Ciência com suas crenças pessoais, os alunos encontrem oportunidades de compreensão da cultura científica, mas mantenham a sua própria visão de mundo e tenham condições de utilizar os conhecimentos científicos no contexto apropriado. Em outras palavras, uma abordagem didática sensível às diferenças culturais resultaria na compreensão de 
duas ou mais áreas de conhecimento bem definidos e compartimentados, de maneira que os estudantes reconheçam que é possível manter suas crenças pessoais e ter domínio de temas científicos.

\section{Agradecimentos}

Às instituições Conselho Nacional de Desenvolvimento Científico e Tecnológico (CNPq), Coordenação de Aperfeiçoamento de Pessoal de Nível Superior (Capes), Núcleo de Pesquisa em Educação, Divulgação e Epistemologia da Evolução Biológica (EdevoDarwin) e Pró- Reitoria de Pesquisa da Universidade de São Paulo (USP).

Ao Prof. Dr. Giuseppe Pellegrini e a toda a equipe do Observa Science in Society, de Vicenza, Itália, pela parceria e colaborações ao longo do desenvolvimento deste estudo.

\section{Referências}

Aikenhead, G. S. (2008). Importation of science programs from Euro-American countries into Asian countries and regions: a recipe for colonization? In Conference of Asian Science Education, 2008, Kaohsiung, Taiwan. Disponível em https://www. researchgate.net/profile/Gabriele_Marranci/publication/227563568_Sociology_ and_Anthropology_of_Islam_a_Critical_Debate/links/54117b840cf29e4a232965e7/ Sociology-and-Anthropology-of-Islam-a-Critical-Debate.pdf

Aikenhead, G. S., \& Jegede, O. J. (1999). Cross-cultural science education: A cognitive explanation of a cultural phenomenon. Journal of research in science teaching, 36(3), 269-287.

Almeida, R., \& Monteiro, P. (2001). Trânsito religioso no Brasil. São Paulo: Perspectiva, 15(3), 92-100.

Berti, A. E., Toneatti, L., \& Rosati, V. (2010). Children's conceptions about the origin of species: A study of Italian children's conceptions with and without instruction. The Journal of the Learning Sciences, 19(4), 506-538.

Bizzo, N. (1991). Ensino de evolução e história do darwinismo. (Tese de Doutorado em Educação, Faculdade de Educação). Universidade de São Paulo, São Paulo.

Bizzo, N. (2011). Understanding and Acceptance of Evolution: Research in Geological Time and Cognition. In M. K., Patairiya, \& M. I. Nogueira (Ed.). Sharing Science. NCSTC/ DST/ ISCOS: India, (pp. 79-94). Disponível em http://www.iscos.org/notices/ sharingscience.pdf\#page $=99$

Bizzo, N., \& El-Hani, C. N. (2009). Darwin and Mendel: evolution and genetics.Journal of Biological Education, 43(3), 108-114.

Boujaoude, S., Wiles, J. R., Asghar, A., \& Alters, B. (2011). Muslim Egyptian and Lebanese students' conceptions of biological evolution. Science \& Education, 20(9), 895-915. 
Bruce, S. (2010). Secularization. In B. S. Turner (Ed.). The new Blackwell companion to the sociology of religion (pp. 125-140). Disponível em https://www.researchgate.net/ profile/Gabriele_Marranci/publication/227563568_Sociology_and_Anthropology_ of_Islam_a_Critical_Debate/links/54117b840cf29e4a232965e7/Sociology-andAnthropology-of-Islam-a-Critical-Debate.pdf

CobernW.W.(1991). Worldviewtheoryandscienceeducation research, NARSTMonograph. Manhattan, KS: National Association for Research in Science Teaching. Disponível em http://scholarworks.wmich.edu/cgi/viewcontent.cgi? article $=1043 \&$ context $=$ science_ slcsp

Cobern W. W. (1996). Worldview theory and conceptual change in science education. Science Education, 80(5), 579-610.

Cobern W. W., \& Loving, C. C. (2001).Defining "science" in a multicultural world: Implications for science education. Science \& Education, 85(1), p. 50-67.

Cobern W. W. (2008). An essay for educators: Epistemological realism really is common sense. Science \& Education,17(4), 425-447.

Collins-Mayo, S. (2012).Youth and religion. An international perspective. Theo-Web. Zeitschriftfuer Religion paedagogik. Academic Journal of Religious Education, 11(1), 80-94.

Crivellaro, F., \& Sperduti, A. (2014). Accepting and understanding evolution in Italy: a case study from a selected public attending a Darwin Day celebration. Evolution: Education and Outreach, 7(13), 1-8.

Davie, G. Resacralization. (2010). In B. S. Turner (Ed.).The new Blackwell companion to the sociology of religion. (pp. 160-177). Disponível em https://www.researchgate.net/ profile/Gabriele_Marranci/publication/227563568_Sociology_and_Anthropology_ of_Islam_a_Critical_Debate/links/54117b840cf29e4a232965e7/Sociology-andAnthropology-of-Islam-a-Critical-Debate.pdf

Donnelly, L. A., Kazempour, M., \& Amirshokoohi, A. (2009). High school students' perceptions of evolution instruction: acceptance and evolution learning experiences. Research in Science Education, 39(5), 643-660.

Hanley, P., Bennett, J., \& Ratcliffe, M. (2014). The Inter-relationship of Science and Religion: A typology of engagement. International Journal of Science Education, 36(7), $1210-1229$.

Hokayem, H., \& Boujaoude, S. (2008). College students' perceptions of the theory of evolution. Journal of Research in Science teaching, 45(4), 395-419.

Kearney, M. (1984). World View. Novato: Chandler \& Sharp.

Novaes, R. (2004). Os jovens "sem religião": ventos secularizantes, "espírito de época" e novos sincretismos. Notas preliminares. Estudos Avançados, 18(52), 321-330. 
Oliveira, G. S. (2015). Estudantes e a evolução biológica: conhecimento e aceitação no Brasil e Itália. (Tese de Doutorado, Faculdade de Educação). Universidade de São Paulo, São Paulo.

Oliveira, G. S., \& Bizzo, N. (2011).Aceitação da evolução biológica: atitudes de estudantes do ensino médio de duas regiões brasileiras. Revista Brasileira de Pesquisa em Educação em Ciências,11(1), 57-79.

Winslow, M. W., Staver, J. R., \& Scharmann, L. C. (2011). Evolution and personal religious belief: Christian university biology-related majors' search for reconciliation. Journal of Research in Science Teaching, 48(9), 1026-1049.

\section{Graciela da Silva Oliveira}

http://orcid.org/0000-0003-0609-8558 Universidade Federal de Mato Grosso (UFMT) Instituto de Biociências Cuiabá, Brasil graciela.ufmt@gmail.com

Nelio Bizzo http://orcid.org/0000-0002-7209-2659 Universidade de São Paulo (USP) Faculdade de Educação Programa de Pós-graduação em Educação São Paulo, Brasil bizzo@usp.br Giuseppe Pellegrini http://orcid.org/0000-0001-9024-3177 Università Degli Studi di Padova Observa - Science in Society Padova, Italia

Submetido em 2 de Outubro 2015

Aceito em 8 de Novembro 2016

Publicado em 30 de Abril de 2017 